\title{
Human quadriceps strength and fatiguability in patients with post viral fatigue
}

\author{
Olga M Rutherford, Peter D White
}

\begin{abstract}
Quadriceps isometric strength, activation and fatiguability were measured in 11 patients with symptoms of fatigue three months after glandular fever or a glandular fever-like illness. Predicted normal and lower limits of normal muscle strength were calculated from height and age. These measures and the fatigue index were compared with a group of healthy students of similar age. Two of the patients were unable to activate fully their muscles. After allowing for this inhibition the group mean (SD) strength was 104 (22)\% of predicted. Although there was no significant difference in the fatigue index between the patients and the control group, there was a trend for the patients to show less fatigue than controls. There was no difference in the muscle results for those patients who were found to have Epstein-Barr virus infections and those who did not. The feelings of weakness and fatigue experienced by the patients could not be explained by either physiological muscle fatigue or lack of effort.
\end{abstract}

Recently much attention has been focused on the chronic fatigue syndromes, an ill-defined group of conditions including neurasthenia, ${ }^{1}$ chronic fatigue syndrome, ${ }^{2}$ effort syndrome, ${ }^{3}$ Da Costas syndrome, ${ }^{4}$ post- viral fatigue syndrome, ${ }^{5}$ fibromyalgia, ${ }^{6}$ Royal Free disease, ${ }^{7}$ and myalgic encephalomyelitis. ${ }^{8}$ As yet there is no consensus regarding the aetiology of the condition. Common symptoms include persistent fatigue and weakness which are often exacerbated by exercise. Symptoms may last up to several years and, as some of the names suggest, the condition often appears to be triggered by a viral infection. Similar symptoms, such as painful muscles and increased susceptibility to fatigue can occur during acute viral infection. ${ }^{9}$

No difference in muscle isometric strength or fatiguability has been found in patients with "effort syndrome". ${ }^{10}$ No reduction in muscle strength has been found in patients with "chronic fatigue syndrome", although an impairment of recovery of maximal isometric strength following endurance testing was found. " The authors admit, however, that this may have been due to reduced motor neuron recruitment. Byrne and Trounce found normal muscle enzyme concentrations in 11 patients with "chronic asthenia and myalgia of obscure aetiology."12

Increased jitter values have been found in some patients by single fibre electromyography ${ }^{13}$ but their physiological significance is uncertain. Arnold et al described in one patient with post-viral fatigue an exaggerated early and sustained fall in tissue $\mathrm{pH}$ with exercise, as measured by phosphorus nuclear magnetic resonance. ${ }^{14}$ However, further work by the same group has shown poor specificity and sensitivity of these muscle abnormalities in "post-viral" fatigue states. ${ }^{15}$ Not one of these studies involved groups of patients with corroborated evidence of infection at onset. Doubt remains therefore about the muscle physiology of patients with genuine corroborated post-infectious fatigue. ${ }^{16}$

During acute viral and other infections, however, Astrom et al found focal deviations in myofibrillar and Z-line organisation and decreased enzyme levels which did not correlate with the severity of myalgia. ${ }^{17}$ Similar, although more extensive alterations are often found in a variety of other more specific muscle disorders. ${ }^{18}$ Friman $^{9}$ found decreased isometric strength in several muscle groups during acute infection compared with recovery. In a prospective study on the effect of sandfly fever Friman and colleagues found decreased strength during but not after fever. ${ }^{19}$ These changes were not accompanied by alterations in the relevant enzymes in serum or muscle nor by altered muscle ultrastructure. The impairment was correlated with the severity of self-reported symptoms, such as myalgia, but not with the severity or duration of fever.

The voluntary testing of maximal strength clearly requires full understanding of the manoeuvre and a high level of motivation. Even when both these requirements are fulfilled the muscle can be inhibited by pain, or fear of pain, from damaged joints or muscle. ${ }^{2021}$ Weakness may therefore be due to submaximal activation of the muscle rather than muscle atrophy. Only one of the studies on patients with chronic fatigue tested for full muscle activation. ${ }^{10}$

Infectious mononucleosis (glandular fever) is a disease anecdotally acknowledged to be associated with delayed convalescence due to fatigue or depression. ${ }^{22}$ Studies of muscle strength and fatiguability in symptomatic patients after definite viral infection have not been reported. In this study we have tested muscle strength and fatiguability in a group of 
symptomatic patients three months after the onset of a glandular fever-like illness. Using a superimposed electrical stimulation technique we have examined the ability of the patients to fully activate their muscle during the strength testing.

\section{Subjects and methods}

Eleven patients were selected from a longitudinal study of 249 patients recovering from an infectious illness. ${ }^{23}$ All 11 had attended their general practitioner and had been sent to St Bartholomew's or Hackney Hospitals, London, for a monospot blood test for infectious mononucleosis. Patients were selected consecutively as complaining of significant physical fatigue and fatiguability two or more months after a glandular fever-like illness, without suffering from an affective illness. The investigators were unaware of the outcome of the test or diagnosis until the study was complete. A control group of 11 young healthy volunteers was recruited from a group of students. Subjects gave their written informed consent for the study which was passed by the Research Ethics Committees of St Bartholomew's and University College Hospitals.

Patients were tested a mean of three months (range 2-4.5 months) after the onset of the viral illness. The test procedure involved a maximal strength test and fatigue protocol of the quadriceps muscle group. Only the right leg was tested. During the strength test maximum activation of the muscle was checked using superimposed stimulation.

Quadriceps strength was determined during a maximal voluntary isometric contraction (MVC). ${ }^{24}$ Subjects were seated in an adjustable straight backed chair with the lower leg dependant and the knee held at $90^{\circ}$. The pelvis was restrained with a lap strap and an inextensible strap was looped around the ankle and attached to a strain gauge at the back of the chair. Subjects were asked to extend the knee against the strap with as much force as possible, and the best of three manoeuvres was recorded as the maximum strength.

Maximal activation of the quadriceps during the MVC was tested using a percutaneous twitch superimposition technique. ${ }^{20}$ This involved percutaneous stimulation of the quadriceps at $1 \mathrm{~Hz}$ via pad electrodes. The voltage was set so that approximately $50 \%$ of the muscle was stimulated. Two twitches were recorded with the muscle at rest; the subject was then asked to perform a maximal contraction with twitches superimposed. During a truly maximal contraction no extra force is generated by the stimulation on top of the voluntary force. Where extra force is generated by the stimulation the true maximum can be estimated from the height of the extra force relative to the height of the twitch before the voluntary contraction.

Fatiguability was tested by repeated isometric contractions of the quadriceps with a target set to $60 \%$ of the MVC. The duty cycle consisted of contractions of 1 second duration with 1 second rest for a total of 20 minutes with the timing controlled by a metronome. Every 5 minutes the subjects performed a maximal effort. At the end of the 20 minutes, or when subjects could no longer maintain the target force, another maximum contraction was performed with superimposed twitches. The fatigue index was expressed as the maximum force achieved after 20 minutes as a percentage of the fresh MVC force.

Patients had serial blood taken for serological testing for antibodies against EpsteinBarr virus, cytomegalovirus, hepatitis $\mathrm{A}$ and C, Toxoplasma gondii, adenovirus and other relevant pathogens. Patients were given a standardised psychiatric interview before muscle testing. ${ }^{25}$

The Student's unpaired $t$ test was used to compare the patient and control groups and the muscle strength of the patients predicted values.

\section{Results}

There were 11 patients (seven female, four male) who had a mean age of 20.9 years (range 16-27) and 11 controls (five female, six male) who had a mean age of 22.5 years (range 20-25). There was no significant difference in sex ratio or age.

The patients varied widely in the amount of time spent in bed and time off work. The mean time in bed was 11 days (range 0-39 days) and the mean time spent off work was 34 days (range 0-87 days).

Seven of the patients had had a primary Epstein-Barr virus infection, one had had hepatitis A. No serological diagnosis was made in the remaining three patients, although all three were recovering from illnesses of glandular fever type, and two had had a positive monospot test and atypical lymphocytosis at onset. There was no difference between the results for strength and fatiguability between the patients who had had EBV infections and those who had not. One patient had alcoholism (Research Diagnostic Criteria ${ }^{26}$ ) drinking an average of 33 units per week. Ten patients had symptoms consistent with a fatigue syndrome. ${ }^{27}$ One patient had fatigue as his only symptom. No patient met the criteria for a depressive illness, anxiety disorder, or somatisation disorder. ${ }^{26}$

In healthy subjects there is a known relationship between height and quadriceps strength..$^{28}$ For each subject the predicted normal and lower limit of normal $(+2 S D)$ strength was calculated from height with adjustments for age and sex. ${ }^{2930}$ All subjects fell within the normal range of strength for their height. All of the control subjects could fully activate their muscles but two of the patients were inhibited. For these two the extra force generated by the twitch was used to calculate the true maximal force of the muscle. As a group the mean (SD) measured strength was $104(22) \%$ of predicted which is not significantly different from $100 \%$ $(p=0.28)$. Using these values the mean measured and predicted strength values for the patients are given in the table. 
Table Quadriceps strength (MVC; $N$, Newtons), predicted strength for height and fatiguability for patients with symptoms of fatigue and normal controls. (Fatigue index only includes those subjects who completed the 20 minutes exercise).

\begin{tabular}{|c|c|c|c|c|c|}
\hline & \multicolumn{3}{|c|}{ Patients } & \multicolumn{2}{|c|}{ Controls } \\
\hline & $\begin{array}{l}M V C \\
(N)\end{array}$ & $\begin{array}{l}\text { Predicted } \\
M V C(N)\end{array}$ & $\begin{array}{l}\text { Fatigue Index } \\
(\%)\end{array}$ & $\begin{array}{l}M V C \\
(N)\end{array}$ & $\begin{array}{l}\text { Fatigue Index } \\
(\%)\end{array}$ \\
\hline $\begin{array}{l}\text { Mean } \\
\text { SD } \\
\mathrm{n}\end{array}$ & $\begin{array}{r}448 \\
99 \\
11\end{array}$ & $\begin{array}{r}444 \\
111 \\
11\end{array}$ & $\begin{array}{l}77 \cdot 4 \\
11 \cdot 1 \\
9\end{array}$ & $\begin{array}{r}514 \\
113 \\
11\end{array}$ & $\begin{array}{c}69 \cdot 7 \\
9 \cdot 5 \\
11\end{array}$ \\
\hline
\end{tabular}

The group mean quadriceps strength for the controls was greater, although not significantly so, than in the patient group ( $p=0.08)$. This may reflect the greater mean height of the control $(1.73 \mathrm{~m})$ compared with the patient $(1.70 \mathrm{~m})$ group caused by the larger number of men in the control group.

As the quadriceps are weight bearing muscles, a relationship also exists between body weight and strength. ${ }^{24}$ The measured strength was $96(24) \%$ of that predicted for weight which was also not significantly different from $100 \%(p=0 \cdot 29)$.

All of the patients and control subjects found the fatigue test strenuous and required a lot of encouragement. Two of the male patients were unable to complete the full 20 minutes of exercise. The group mean fatigue score for the patients who completed the 20 minutes was $77 \cdot 4(11 \cdot 1) \%$ and for the whole group 73.7 $(13.7) \%$. The mean fatigue score for the controls was $69 \cdot 7(9 \cdot 5) \%$. Therefore there was a remarkable trend for the patients to show less fatigue than the healthy controls, whether completing the fatigue protocol $(p=0.06)$ or not $(p=0 \cdot 2)$. It seemed that the control subjects needed greater encouragement in completing the protocol than the patients.

\section{Discussion}

We have found normal strength and fatiguability in a group of fatigued patients three months following a viral infection, primarily EBV infectious mononucleosis. At the time of testing the patients felt fatigued with limited exercise tolerance. The subjective feeling of fatigue, which is well known following this type of illness, could not be explained by peripheral changes in muscle isometric force generation or fatiguability. At the same time, all but two patients were able to generate their predicted maximal strength and showed normal fatiguability. Thus we found no evidence that reduced effort has an aetiological role in acute post-viral fatigue for the large majority of patients. No attempt was made to rate the perceived effort during the fatigue test but it appeared to the investigator, rather surprisingly, that the patients found it easier to complete than the controls. Lloyd et al found that patients with a chronic fatigue syndrome (duration greater than six months) perceived their muscle effort over $\mathbf{4 5}$ minutes exercise as "large or very large", but their perception was not significantly different from healthy controls doing the same muscle work. ${ }^{31}$ However, Riley et $a l^{32}$ found that patients with a chronic fatigue syndrome (duration greater than six months) perceived muscle work as more effort than healthy controls.

Human muscle strength is often discussed as if it were a quantity which is easily defined and measured. However, expression of the strength of a muscle such as the quadriceps, even during a simple movement, is the result of a combination of factors which can be broadly classified as either central or peripheral. Peripheral factors may be thought of as those which determine the intrinsic strength of the individual muscle, such as size and fat content and is the strength that would be measured if the muscle was maximally activated by tetanic stimulation. Central factors include volition and inhibition which affect the activity of the motor neurons..$^{2021}$ Muscle weakness can therefore result from changes in either central or peripheral factors. It is therefore important to assess central factors when trying to measure the maximal voluntary strength of a muscle. The majority of patients in this study had no central inhibition to force generation; only two being unable to maximally activate their quadriceps. We do not know if this inhibition was due to a lack of understanding of the manoeuvre, altered motivation, pain or a fear of pain from muscle or joints. Most healthy subjects have been found to be able to maximally activate the majority of muscle groups. ${ }^{2033-35}$ However, motivation may be particularly important during acute infection as subjects may feel unable to exert a maximal effort. The pain and stiffness often felt in joints and muscles during flu-like illnesses may also inhibit muscle contraction. Unfortunately, none of the studies which have measured strength during these acute stages of an illness have looked at muscle activation.

Stokes et $a l^{10}$ also measured quadriceps strength and activation in a different group of patients with "effort syndrome" not necessarily following a viral infection and found essentially the same results as reported here. A few patients were unable to fully activate their muscle and the rest had normal strengths for their body weight. It is of interest that the patients who showed inhibition also stopped a cycle exercise test before their predicted maximal heart rate was reached. They also found no difference in fatiguability of the adductor pollicis between the patients and a control group. They suggested that the reduced exercise capacity in this group may be due to a reduced tolerance of effort symptoms rather than an intrinsic muscle weakness.

In our study only one limb was exercised using isometric (static) contractions. This is unlike most movements in everyday life where two limbs are normally working dynamically in a rhythmic fashion, with more than one muscle group exercising. It may be that any exercise limitation will only become apparent when a large muscle mass is involved which places a greater burden on the cardiovascular and respiratory systems. A final reason for not finding significant differences between controls and patients might be a statistical type 2 error, although a larger study might replicate our findings that showed less fatigue in patients. 
It is often difficult to know what advice to give to a patient who is suffering from a limited exercise capacity following a viral infection. Rest is important in the acute stages of an infection. If rest is continued too long, however, then a vicious circle can develop in which inactivity leads to a loss of aerobic fitness which will cause a greater feeling of weakness, muscle pain and exercise intolerance. ${ }^{273637}$ Riley et $a l^{32}$ have recently shown reduced aerobic work capacity in patients with a more chronic fatigue syndrome. One approach to treatment is therefore a programme of rehabilitation which involves a gradual return to exercise which starts with gentle exercise such as stretching and gradually builds up exercise tolerance. ${ }^{27} 38 \mathrm{McCain}^{39}$ showed that such a programme improved fitness and was superior to placebo in relieving symptoms in patients with "fibromyalgia", a condition with many similarities to the chronic fatigue syndrome. ${ }^{27}$ Furthermore, Repsher and Freehern $^{40}$ showed that a programme of exercise given to patients recovering from infectious hepatitis had no detrimental effect on convalescence. We suggest this may be a successful means of hastening convalescence so long as clinically active signs of infection, such as fever and pharyngitis, are absent. Should symptoms last longer than six months a careful review of all possibly perpetuating factors should be made and other treatable disorders managed. 2741

We thank Dr J Amess and Dr J Burman for selecting cases. Professor H Stern, Professor R Heath, Dr H Kangro, and Mrs S Grover provided serological diagnoses. Professor A W Clare gave advice and support.

PDW was supported by a Mental Health Foundation training fellowship.

1 Beard GM. Neurasthenia, or nervous exhaustion. Boston Medical and Surgical Journal 1869;3:217-21.

2 Holmes GP, Kaplan JE, Gantz NM, et al. Chronic fatigue syndrome: a working case definition. Ann Intern Med 1988;108:387-9.

3 Newham DJ, Edwards RHT. Effort Syndromes. Physiotherapy 1979;65:52-6.

4 Wood P. Aetiology of Da Costa's syndrome. BMJ 1941; i:845-51.

5 Behan PO, Behan WMH, Bell EJ. The postviral fatigue syndrome-an analysis of the findings in 50 cases. $J$ Infect syndrom:-2an an

6 Goldenberg DL. Fibromyalgia syndrome: an emerging but controversial condition. JAMA 1987;257:2782-7

7 Ramsay MA. Post-viral fatigue syndrome: the saga of Royal Free disease. London: Gower Medical, 1986.

8 Acheson ED. The clinical syndrome variously called benign myalgic encephalomyelitis, Iceland disease, and epidemic neuromyasthenia. Am J Med 1959;26:569-95.

9 Firman G. Effect of acute infectious disease on isometric muscle strength. Scand J Clin Lab Invest 1977;37:303-8.

10 Stokes MJ, Cooper RG, Edwards RHT. Normal muscle strength and fatiguability in patients with effort syndromes. $B M J$ 1988;297:1014-7.

11 Lloyd AR, Hales JR, Gandevia SC. Muscle strength, endurance and recovery in the post-infection fatigue syndrome.
12 Byrne E, Trounce I. Chronic fatigue and myalgia syndrome mitochondrial and glycolytic studies in skeletal muscle. mitochondrial and glycolytic studies in skele.

Neurol Neurosurg Psychiatry 1987;50:743-6.
13 Jamal GA, Hansen S. Electrophysiological studies in the postviral fatigue syndrome. Lancet 1988;i:146-50.

4 Arnold DL, Bore PJ, Radda GK, Styles P, Taylor DJ Excessive intracellular acidosis of skeletal muscle on exercise in a patient with post-viral exhaustion/fatigue syndrome. Lancet 1984;i:1367-9.

5 Yonge RP. Magnetic resonance muscle studies: implication for psychiatry. $J R$ Soc Med 1988;81:322-6.

16 Sharpe MC, Archard LC, Banatvala JE, et al. A reportchronic fatigue syndrome: guidelines for research. $J R$ Soc Med 1991;84:118-21.

17 Astrom E, Friman G, Pilstrom L. Effects of viral and mycoplasma infections on ultrastructure and enzyme activities in human skeletal muscle. Acta Pathol Microbiol Scand $(A)$ 1976;84:113-22.

18 Sewry $C$. Ultrastructural changes in diseased muscle. In Dubowitz V, ed. Muscle biopsy. A practical approach. Dubowitz V, ed. Muscle biopsy. A practical

19 Friman G, Wright JE, Ilback NG, et al. Does fever or myalgia indicate reduced physical performance capacity in viral infections? Acta Med Scand 1985;217:353-61.

20 Rutherford OM, Jones DA, Newham DJ. Clinical and experimental application of the percutaneous twitch superimposition technique for the study of human muscle activation. J Neurol Neurosurg Psychiatry 1986;49: 1288-91.

21 Stokes MJ, Young A. The contribution of reflex inhibition to arthrogenous muscle weakness. Clin Sci Mol Med 1984;67:7-14.

22 Straus SE. The chronic mononucleosis syndrome. J Infect 1988;157:405-12.

23 White PD, Clare AW. Psychological sequelae of Infectious Mononucleosis. (Abst 117D). American Psychiatric Mononucleosis. (Abst 117D). American Psych
Association Annual meeting 1990, New York, USA.

24 Edwards RHT, Young A, Hosking GP, Jones DA. Human skeletal muscle function: description of tests and norma values. Clin Sci Mol Med 1977;52:283-90.

25 Endicott J, Spitzer RL. A diagnostic interview: the schedule for affective disorders and schizophrenia. Arch Gen Psychiatry 1978;35:837-44.

26 Spitzer RL, Endicott J, Robins E. Research Diagnostic criteria: rationale and reliability. Arch Gen Psychiatry 1978;35:773-82.

27 White PD. Fatigue and chronic fatigue syndromes. In: Bas C, ed. Somatization: physical symptoms and psychological illness. Oxford: Blackwell Scientific, 1990:104-40.

28 Parker DF, Sacco R, Round JM, Jones DA A crosssectional survey of upper and lower limb strength in boys and girls during childhood and adolescence. Ann Hum Biol 1990;17:199-211.

29 Rutherford OM. The determinants of human muscle strength and the effects of different high resistance training regimes (PhD Thesis). University of London, 1986.

30 Jones DA, Rutherford OM. The effects of ageing and osteoporosis on the force generating capacity of the quadriceps muscle in women. J Physiol 1990;423:84P.

31 Lloyd AR, Gandevia SC, Hales JP. Muscule performance, voluntary activation, twitch properties and perceived effort in normal subjects and patients with chronic fatigue syndrome. Brain (in press)

32 Riley M, O'Brien CJ, McCluskey DR, Bell N, Nicholls P. Aerobic work capacity in patients with chronic fatigue syndrome. BMJ 1990;301:953-6.

33 Belanger AY, McComas AJ. Extent of motor unit activation during effort. J Appl Physiol 1981;51:1131-5.

34 Bellemare F, Woods JJ, Johansson R, Bigland-Ritchie B. Motor-unit discharge rates in maximal voluntary contractions of three human muscles. J Neurophysiol 1983; 50:1380-92.

35 Merton PA. Voluntary strength and fatigue. J Physiol 1954;123:553-64.

36 Lancet. Aching muscles after exercise. Lancet 1987;ii: $1123-4$.

37 Saltin B, Blomqvist G, Mitchell JH, Johnson RL, Wildenthal K, Chapman CB. Response to exercise after bedrest and after training. Circulation (Suppl 7) 1968;38:1-78.

38 Edwards RHT. Muscle fatigue and pain. Acta Med Scand (Suppl) 1986;711:179-88.

39 McCain GA. Role of physical fitness training in the fibrositis/ fibromyalgia syndrome. Am J Med (Suppl 3a) 1986;81: 73-7.

40 Repsher LH, Freehern RK. Effects of early and vigorous exercise on recovery from infectious hepatitis. $N$ Engl $J$ Med 1969;281:1393-6.

41 Wessely S, David A, Butler S, Chalder T. Management of chronic (post-viral) fatigue syndrome. JR Coll Gen Pract 1989;39:26-9. 